\title{
Association between Awareness Regarding Elective Cesarean Section Complications and (Age, Educational Level) at Maternity and Delivery Teaching Hospital in Holy Karbala City
}

\author{
*Buraq Adnan Abdul Redha ${ }^{1, * *}$ Dr. Suhad H. Khairi, Ph.D ${ }^{2}$. \\ *! (Nursing college / University of Baghdad, Republic of Iraq) \\ ***(Assistant Prof. / Maternal and Neonatal Nursing Department / College of Nursing / University of Baghdad).
}

\begin{abstract}
Objectives: the study aimed to find out the relationship between awareness regarding caesarean section complications and certain demographic characteristics (age and education level)

Method: A purposive sampling "Non probability" consists of one hundred women at reproductive age who have previous elective cesarean section or planned for elective cesarean section, at Maternity and Delivery Teaching Hospital in Holy Karbala City. Data collection carried out from 31May to 16thAugust 2016. Validity was determined through a panel of experts and reliability of the questionnaire through of pilot study. The data was analyzed by using descriptive and inferential statistical procedures and the data were collected through interview technique.

Results: The findings of the study show that the highest percentage (23\%) of the study sample is within age group (15-19) years, (28\%) of the study sample are graduates of Primary school, (42\%) of the study sample have previous elective cesarean section, regarding the main cause for choosing elective cesarean section, (48\%) of the study sample are afraid of normal labor pain and that there was a lack of awareness among study sample concerning elective cesarean section complication

Conclusion: There are a statistical significant relationship between awareness and (age, educational level).

Keywords: awareness, elective cesarean section, complications, age, educational level.
\end{abstract}

\section{Introduction}

Caesarean section, also commonly known as C-section, is an operational procedure, which one or more incisions are done through women's abdomen and uterus to born one or more babes. A C/S is perform when a natural delivery would put the life of baby or mother life and there health at risk. Some are performing on demand without medical indications to do, so it should be Caesarean section done only when there is a medical reason, it is based just on medical need to improve the outcome for the mother or child. The WHO recommends that it should be based just on a medical reason $(1,2,3)$. Caesarean section on maternal request/demand (CSMR) is a primary caesarean delivery performed at the request of the pregnant women in the absence of any medical reason or obstetric indications (4). Nowadays, unfortunately, having a CS has become a culture for escaping pain and has influenced public health. This is when CS imposes more risk to the mother, compared to vaginal delivery, and includes complications such as endomyometritis, bleeding, thromboembolism, preterm labor and mortality (in mother), respiratory distress syndrome, resistant pulmonary hypertension, and damages like injury, bruise, or other traumas in infant(5). In most of the developed countries, it has been tried to reduce CS and its complications by interventions such as health care provider's education and change in their attitude (6).In Iran, some strategies have been made to reduce CS. For instance, it has been reported a reduction in rate of CS by $15 \%$ through mothers' education and their psychological and mental preparation to have a natural delivery (5).

\section{Methodology}

Across section study consist of one hundred married women whose at reproductive age. The data were obtained through face to face interview. The approximate time for interviewing each woman was (15-20) minutes to complete the questionnaire format during 15 June to 16th August 2016. Determine validity and reliability of questionnaire through of pilot study. The study instrument consists of three parts Part One/ SocioDemographic information: It includes the following variables; Age, Educational level for woman, Occupation, Residence, Part Tow/ Reproductive Information: It includes (Parity, Gravity , number of Abortion, Number of living children, number of dead children, type of delivery. Part Three: Women awareness regarding elective cesarean section complications. This part consist of three divisions• First: Women's attitude $(6$ items $) \cdot S e c o n d$ : Women's perception of complications of elective caesarean section (4 items) • Third: Women's knowledge, this consist of two parts, the first part include maternal complications (Short -term complications (10 item ) and 
Long-term complications ( 8 item) $)$ and the second part include a newborn Complications (7 item) of elective cesarean section

Ethical consideration: Verbal consent from each woman of the study sample was obtained, and the participation was confidential, voluntary, anonymous, and the information was for the research purposes only.

\section{Results}

Table (1): Distribution of Study Sample According to demographical characteristics

\begin{tabular}{|c|c|c|c|}
\hline Characteristics & Groups & Freq. & $\%$ \\
\hline \multirow[t]{8}{*}{ Age Group } & $15-19$ & 23 & $23 \%$ \\
\hline & $20-24$ & 20 & $20 \%$ \\
\hline & $25-29$ & 19 & $19 \%$ \\
\hline & 30-34 & 15 & $15 \%$ \\
\hline & 35-39 & 15 & $15 \%$ \\
\hline & $\square \mathbf{4 0}$ & 8 & $8 \%$ \\
\hline & Total & 100 & $100 \%$ \\
\hline & \multicolumn{3}{|c|}{ Mean \pm SD $=28.65 \pm 7.11$} \\
\hline \multirow{3}{*}{ Residence } & Rural & 76 & $76 \%$ \\
\hline & Urban & 24 & $24 \%$ \\
\hline & Total & 100 & $100 \%$ \\
\hline \multirow{8}{*}{ Level of Education } & Not read and write & 20 & $20 \%$ \\
\hline & Read and write & 4 & $4 \%$ \\
\hline & Primary school & 28 & $28 \%$ \\
\hline & Secondary school & 14 & $14 \%$ \\
\hline & Intermediate school & 9 & $9 \%$ \\
\hline & Institute graduate & 11 & $11 \%$ \\
\hline & College graduate & 14 & $14 \%$ \\
\hline & Total & 100 & $100 \%$ \\
\hline \multirow[t]{3}{*}{ Occupation } & Housewives & 82 & $82 \%$ \\
\hline & Employees & 18 & $18 \%$ \\
\hline & Total & 100 & $100 \%$ \\
\hline
\end{tabular}

This table indicates that the highest percentage (23\%) of the study sample are within age group (15-19) years with mean and SD $(28.65 \pm 7.11)$, while the lowest percentage $(8 \%)$ of them are 40 years or more. Regarding to Residence the highest percentage $(76 \%)$ of the study sample are live in urban areas, while the lowest percentage (24\%) of them are live in rural areas. Concerning to the level of education, the highest percentage (28\%) of the study sample graduated from Primary school while the lowest percentage (4\%) of them can read and write. Regarding to the Occupation the highest percentage $(82 \%)$ of the study sample are housewives, while the lowest percentage (18\%) of them are employees.

Table (2): Distribution of Study Sample According to Reproductive Characteristics

\begin{tabular}{|c|c|c|c|}
\hline \multicolumn{2}{|c|}{ Reproductive Characteristic } & Freq. & $\%$ \\
\hline \multirow[t]{5}{*}{ Gravida } & Prime gravida & 18 & 18 \\
\hline & $2-3$ & 50 & 50 \\
\hline & $4-5$ & 23 & 23 \\
\hline & $\square \mathbf{6}$ & 9 & 9 \\
\hline & Total & 100 & 100 \\
\hline \multirow[t]{5}{*}{ Para } & Nil para & 2 & 2 \\
\hline & $1-2$ & 65 & 65 \\
\hline & $3-4$ & 29 & 29 \\
\hline & $\square \mathbf{5}$ & 4 & 4 \\
\hline & Total & 100 & 100 \\
\hline \multirow[t]{5}{*}{ Delivery Mode } & Pervious Elective Cesarean section & 42 & 42 \\
\hline & Planned elective Cesarean section & 18 & 18 \\
\hline & Normal & 8 & 8 \\
\hline & elective Cesarean + Normal & 32 & 32 \\
\hline & Total & 100 & 100 \\
\hline \multirow[t]{3}{*}{ No. of Dead birth } & Non & 93 & 93 \\
\hline & 1 & 7 & 7 \\
\hline & Total & 100 & 100 \\
\hline \multirow[t]{4}{*}{ No. of Abortion } & Non & 59 & 59 \\
\hline & $1-2$ & 37 & 37 \\
\hline & $3-4$ & 4 & 4 \\
\hline & Total & 100 & 100 \\
\hline \multirow[t]{2}{*}{ No. of Living birth } & Nil & 2 & 2 \\
\hline & $1-2$ & 62 & 62 \\
\hline \multirow{3}{*}{ 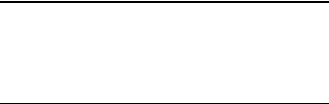 } & $3-4$ & 25 & 25 \\
\hline & $\square \mathbf{5}$ & 4 & 4 \\
\hline & Total & 93 & 93 \\
\hline
\end{tabular}


Freq. $=$ Frequency, $\%=$ Percentage, No. $=$ sample size,

Table (2) shows that the highest percentage (50\%) of sample have (2-3) pregnancies, while the lowest percentages $(9 \%)$ of them have (6 and more) pregnancies. Concerning the parity, the highest percentage $(65 \%)$ of the study sample have (1-2) deliveries, while the lowest percentages (4\%) of them have 5 and more deliveries. Concerning the mode of delivery: the highest $(42 \%)$ of the study sample have previous elective cesarean section, while the lowest percentage $(8 \%)$ of them have normal vaginal labor. Concerning the number of dead birth: the majorly (93\%) of the study sample do not have dead birth, while the lowest percentage (7\%) of them have one dead birth. Concerning the number of abortion: more than half (59\%) of the study sample have no history of abortion, while the lowest percentages (4\%) of them have (3-4) abortions. Concerning the number of living children: the highest percentage $(62 \%)$ of the study sample have (1-2) living child, while the lowest percentages $(2 \%)$ of them do not have living child.

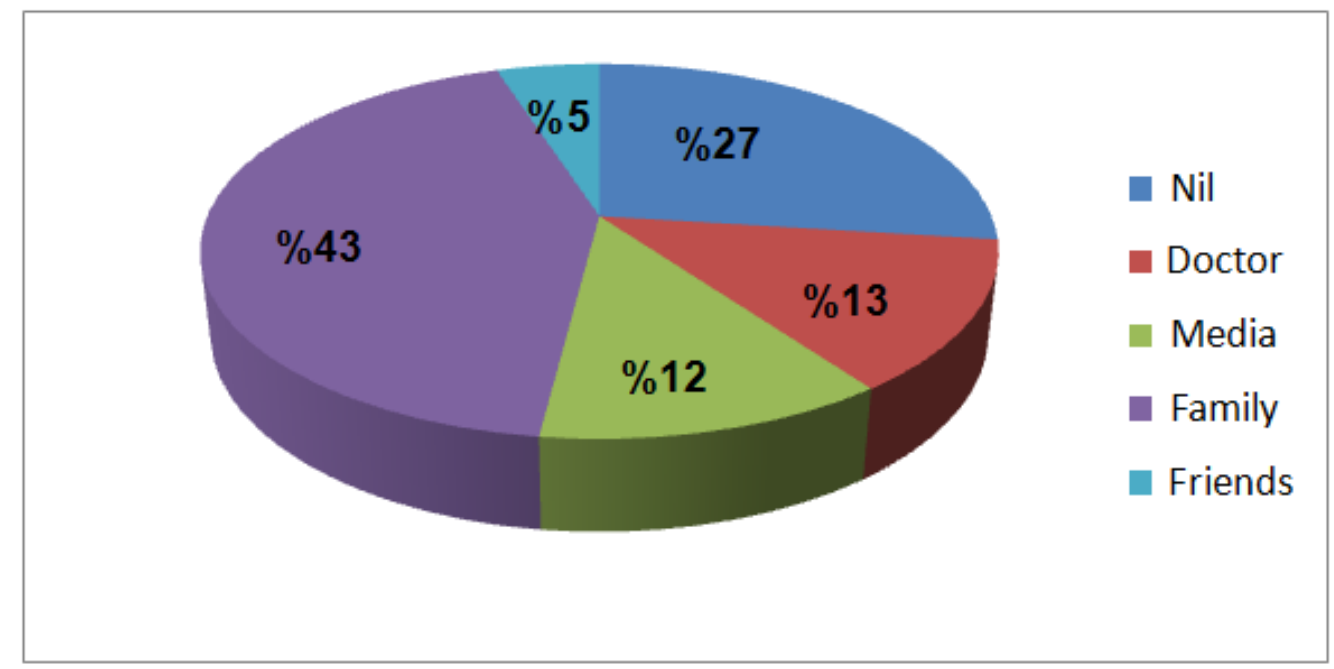

Figure (1) Sources of Elective Cesarean Section Complications Knowledge

Figure (1) shows that the highest percentage $(43 \%)$ of the study sample get their source of knowledge from families, while the lowest percentage $(5 \%)$ of study sample have no source of knowledge about elective cesarean section complications.

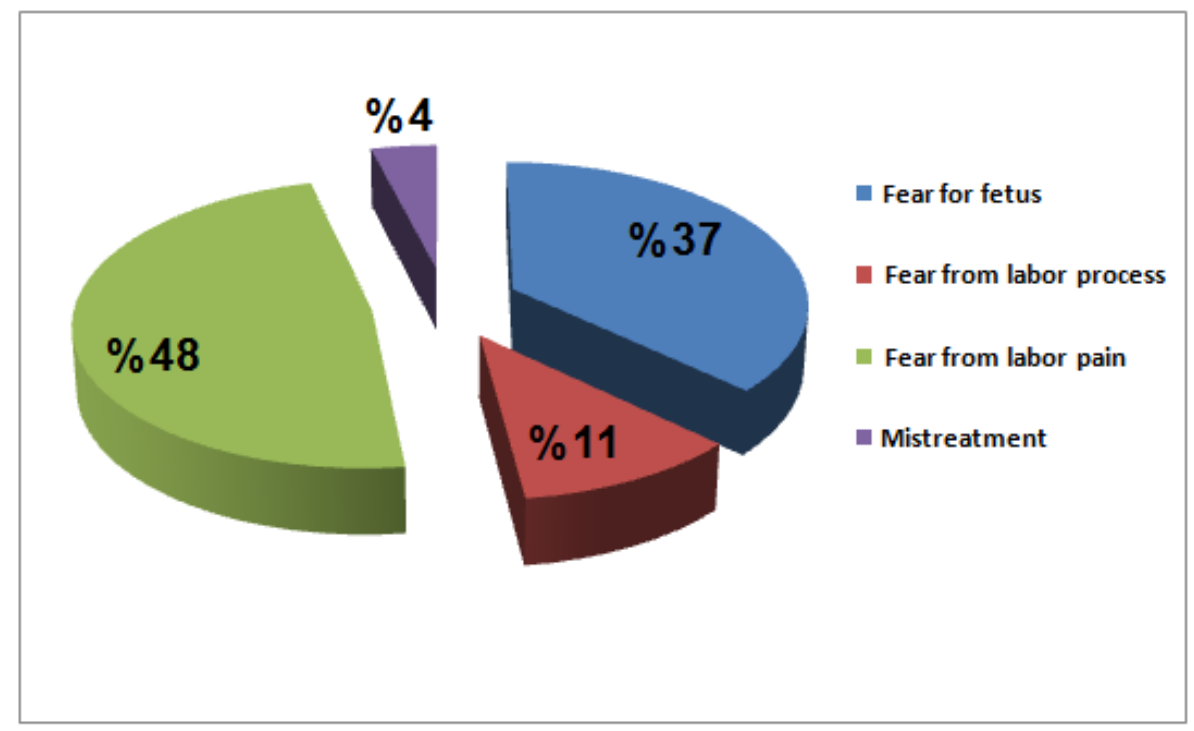

Figure (2): Causes of Choosing Elective Cesarean Section

Figure (2) shows that the highest percentage $(48 \%)$ of the study sample have fear from labor pain, while the lowest percentage $(4 \%)$ of study sample have fear from mistreatment . 
Table (3): Distribution Of Study Sample According to Awareness Characteristics

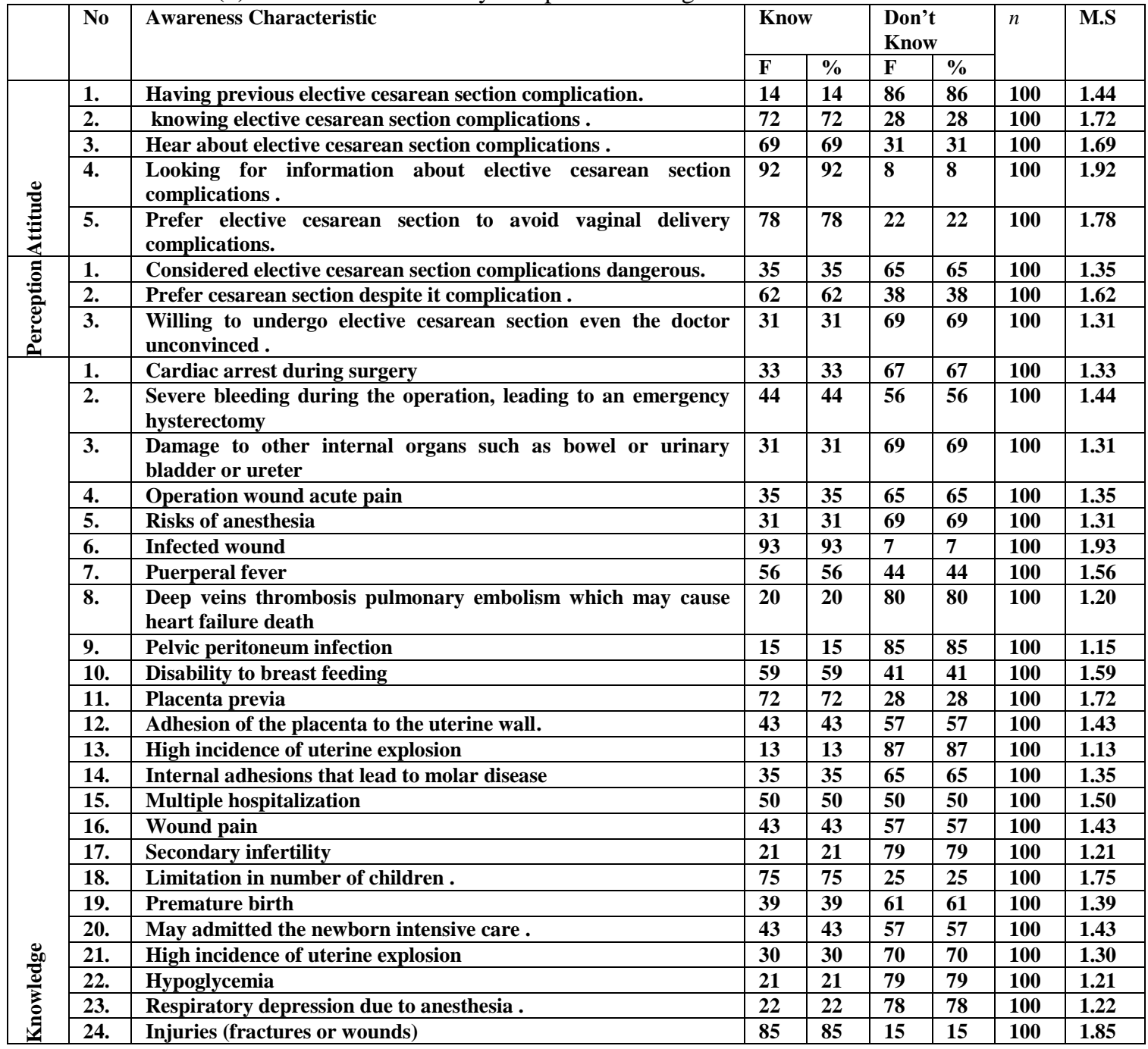

F=Frequency, \%=Percentage, Cut-off point $=1.5$, M.S $=$ Mean Score, $n=$ sample size.

Table (3) shows that the highest mean of score (1.92) of the attitude characteristic is related to Looking for information about elective cesarean section complications, while the lowest mean score (1.44), which considered under cut off point, refers to previous elective cesarean section complication .Concerning perception characteristic : the highest mean of score (1.62) related to Prefer cesarean section despite it complications , while the lowest mean of score (1.31) refer to Decide about elective cesarean section .Concerning Knowledge about elective cesarean section complications characteristic : the highest mean of score (1.93) is related to infected wound, while the lowest mean of score (1.13), which considered under cut off point, refers to High incidence of uterine explosion .

Table (4): Relationship Between Awareness, and both Age Group and Educational Level

\begin{tabular}{|r|r|r|r|r|r|r|}
\hline Awareness & \multicolumn{3}{|c|}{ Age group } & \multicolumn{3}{|c|}{ Educational level } \\
\cline { 2 - 7 } & $\boldsymbol{X}^{2}$ & df & Sig. & $\boldsymbol{X}^{2}$ & Df & $\begin{array}{r}\text { Sig. } \\
\mathbf{0 . 0 5}\end{array}$ \\
\hline Variables & & & & & & $\mathbf{0 . 0 0 0}$ \\
\hline Attitude & 500.000 & 11 & $\mathbf{0 . 0 0 0}$ & 499.000 & 13 & $\mathbf{0 . 0 0 0}$ \\
\hline Perception & 300.000 & 11 & $\mathbf{0 . 0 0 0}$ & 286.000 & 13 & $\mathbf{0 . 0 0 0}$ \\
\hline Knowledge & 2570.000 & 11 & $\mathbf{0 . 0 0 0}$ & 2412.000 & 13 & \\
\hline
\end{tabular}

Table (4) shows that there is a highly statistical significance between attitude, perception and knowledge and (Age group and Educational level). 


\section{Dscussion}

The findings of the present study have indicated that the highest percentage (23\%) of the study sample are at age (15-19) year as shown in table (1), an exceptionally high rate of elective cesarean section of $(48.21 \%)$ in adolescents and (51.11\%) in mothers aged more than 30 years $(n=100)(7)$. from (247) study's participant women, the majority of them $(42.5 \%)$ were younger than 25 years (8). Regarded Residence, the highest percentage $(76 \%)$ of the study sample their residences are urban as shown in table (1). More than half (67.21) of women who had chosen elective C/S their residence in the city (9). Regarding educational level, the highest percentage (28\%) of the study sample graduated from Primary school as shown in table (1), the higher level of education was associated with preference for C-section(10).women with low level of education had no knowledge of ceaserean section, like wise women with highest level of education $(\mathrm{p}<0.00)$ had the highest level of knowledge about cesarean section (11). In another study, in Brazil it was concluded that the highly educated women had a significantly higher preference for $\mathrm{C}$-section and also experienced a higher rate of $\mathrm{C}$-section (12). Regarding Occupation, the highest percentage (82\%) of the study sample were housewives as table (1). The women with cesarean section request rate was higher among with housewives.12

The result of the study shows that the highest percentage (50\%) of sample has (2-3) pregnancies as shown in table (2). Around 70\% of (156) women were in their second pregnancy preferred cesarean section (13) . Most of the pregnant women who chose cesarean section were in their first pregnancy and labor (9). Concerning the parity, the highest percentage (65\%) of the study sample have (1-2) deliveries. There has been a relationship between higher risk of elective $\mathrm{c} / \mathrm{s}$ and null parity (14). Concerning the mode of delivery, the highest percentage $(42 \%)$ of the study sample had previous elective cesarean section. A previous history of ceaserean section has been the main factor in selected a subsequent delivery and keeping the ceaserean section rate in developed countries; forty six percentage $(64.2 \%)$ of pregnant women who had previous caesarean section choose to the repeat the procedure (15). Concerning the number of abortion: more than half $(59 \%)$ of the study sample had no history of abortion as shown in table, previous history of abortion were considered as risk factors for choosing C-section (2) (16). About number of living birth more than half (62\%) of study sample have (1-2) of living child, the women who had only one child prefer a cesarean section procedure, that represent woman's perception elated to effectiveness of cesarean section as a way to survive newborn and avoid stillbirth and birth complications (17). Concerning the source of knowledge, the highest percentage (43\%) of the study sample their source of knowledge is family members (sister, brothers wife, aunt... etc) as shown in figure (1). The friends or relatives $(54.7 \%$ ), media $(24.5 \%)$ and health workers $(20.8 \%)$, are the most common source of cesarean section complications information. Concerning the cause for choice elective cesarean section (8) , the highest percentage $(48 \%)$ of the study sample, have chosen elective cesarean section because they are afraid of labor pain is the cause of choice elective cesarean section as shown in Figure (2), fearing to lose baby and labor pain were the main causes that stay behind the women who chose cesarean section (18) . There were many causes that stand by elective cesarean section without medical reason which are, fearing of labor pain, date or time of birth, that traditionally believed to be a good news and the belief that baby's brain will be protect if deliver by C/S) (19). The decision making process which influenced by the perceptions and certain factors such as family support, self-control, beliefs, value, expectation of birth, reasons for cesarean section performing and traumatic events in woman's life (20), the main reason for turning to cesarean section is intense fear from pain associated with natural delivery and unawareness about cesarean complications(21). From (77.2\%) of women who prefer vaginal delivery considered cesarean section dangerous procedure, while $(47.3 \%)$ of them believed that cesarean section was more safer than vaginal delivery and (68.5\%) who encourage cesarean section believed that it was less painful and (44\%) of women, who encourage vaginal delivery considered C/S was more painful (8) There is a highly statistical significance between knowledge and (Age group and Educational level) as shown in table (4), the level of knowledge among (360) of pregnant women about complications of cesarean section was good in $(43.2 \%)$, and poor in $(18.4 \%)$ of the mothers. $68.1 \%$ of them selected vaginal delivery (NVD) and $(31.9 \%)$ delivered using $\mathrm{C} / \mathrm{S}$. There was a significant association between the knowledge of pregnant women about complications of cesarean section and choosing the type of delivery ( $\mathrm{p}=0.04)$ (9). Other studies show that mothers' knowledge of disadvantages and complications of the cesarean section has not reached an appropriate level and there is still a wrong attitude toward cesarean sections (22) There is a poor knowledge of mothers regarding maternal and fetal complications of C-section, and women with a lower level of knowledge and higher attitude toward C-section were more likely to prefer this mode of childbirth (23), on pregnant women admitted in heath care centers, result demonstrated that most of the pregnant women under study had moderate knowledge and the number of women with high knowledge was low (24).

\section{Conclusions}

The study's results concluded that the highest percentages of the study sample were young or adolescent women with low educational level have low awareness of the consequences of elective cesarean section. From one hundred women, who have chosen cesarean section, there is a statistical significant relationship between awareness and women age and educational level. 


\section{Recommendations}

1. Apply information for pregnant women by nurses and midwives, during antenatal period regarding methods of delivery, its signs, characteristics, and complications, this will enable women to choose their decision through primary health care centers.

2. Obstetricians put an ethical consideration in their clinical and evaluate each case before cesarean section carry out on request.

3. It is suggested to use role play method to educate women to reduce the rate of elective cesarean sections through mass media.

4. Cooperation between the Ministries of Education and Health to raise awareness among female students through provide lectures, pamphlets and videos concerning elective cesarean section complications.

5. Change woman perception during antenatal period, through engage man in decision making after clarifying the complications of elective cesarean sections for both.

\section{Referencse}

[1] WHO, ceaserean section, 2010

[2] WHO, Statement on Caesarean Section Rates, 2015

[3] Finger C., Caesarean section rates skyrocket in Brazil, Lancet 362 (9384) 2003 .( PMID)

[4] Kalish RB., McCullough LB., Chervenak FA. , Patient choice caesareanm delivery: ethical issues, CurrOpinObstetGynecol, 20:116-119 , 2008, cited in Wang B. , Zhou L. , Coulter D. , Liang H. , Zhong Y. , Guo Y. , Effects of caesarean section on maternal health in low risk nulliparous women, 2010

[5] Navaee M. and Abedian Z.,Effect of role play education on primiparous women's fear of natural delivery and their decision on the mode of delivery, Iran J Nurs Midwifery Res., Jan-Feb; 20(1): 40-46, 2015

[6] Gunnervik C, Josefsson A, Sydsjo A, Sydsjo G. Attitudes mode of birth among Swedish. Midwifery.2010;26:38-44. (PubMed)

[7] Ray D., Fetomaternal outcome in mothers aged 30 years and above compared to mothers aged 19 yrs and below. Pg -73 , cited in Indian Medical Gazette, MARCH 2013.

[8] Ajeet S., Jaydeep N., Nandkishore K, Nisha R., Women's knowledge, perceptions, and potential demand towards caesarean section, National Journal of Community Medicine, Sept; Vol 2 ,Page 244, 2011.

[9] Ghasvari M., Rahmanian V., Rahmanian K. Knowledge of pregnant women in the southwest Iran about complications of cesarean section, 2009, cited in Journal of Jahrom University of Medical Sciences, Summer 2012; Volume 10, Number 2 .

[10] Silver RM., Landon MB., Rouse DJ. , Leveno KJ., Spongetal., Maternal morbidity associated with multiple repeat cesarean deliveries, Obstetrics \& Gynecology, 107(6):1226, 2006, cited in Becher L. and Stokke S., Indications for Cesarean Section in St. joseph Medical Hospital, Moshi, Tanzania , OB-GynSognsvannsveien, 20 NO-0027 Oslo, 2013

[11] Delavar B., Ahmad-Nia S., Eini-Zinab H., Kazemipour S., Mehryar AH., Naghavi M., Caesarean section in the Islamic Republic of Iran, East Mediterr Health J, 15:1389-98, 2009. ( PubMed).

[12] Rebelo F., da Rocha CM., Cortes TR., Dutra CL., Kac G., High cesarean prevalence in a national population-based study in Brazil, ActaObstetGynecolScand, 89:903-8, 2010.(PubMed)

[13] Faisal-Cury A. and Rossi Menezes P., Factors associated with preference for cesarean delivery, Rev. SaúdePública vol.40 no.2 São Paulo Apr. 2006

[14] Luthy DA, Malmgren JA, Zingheim RW, Leininger CJ. Physician contribution to a cesarean delivery risk model. Am $\boldsymbol{J}$ ObstetGynecol, 188(6):1579-87, 2003.

[15] Martin JA., Hamilton BE., Ventura SJ., Menacker F., Park MM., Sutton PD., Births: final data for 2001. Natl Vital Stat Repr. 2002;51(2):1-103, Cited in Cury A., and Mário F. Factors associated with preference for cesarean delivery , 2005.

[16] Flores L., Gonzalez GJ., Trejo J., Vega G., Cabrera CE., , et al. Risk factors in cesarean section, GinecolObstetMex, 76:392-7, 2008, cited in J Res Med Sci, Nov; 18(11): 943-950, 2013. (PubMed)

[17] Sufang G., Padmadas S. S., Fengmin Z., Brown J. J., \& Stones R. W. , Delivery settings and caesarean section rates in China, Bulletin of the World Health Organization , 85, 755-762, 2007, cited in Ajeet S., Jaydeep N., Nandkishore K, Nisha R., Women's knowledge, perceptions, and potential demand towards caesarean section , National Journal of Community Medicine, Sept; Vol 2 ,Page 244, 2011.

[18] Khairi S., Reason for pregnant women to choseceaserean section in Bahgdad city , Journal of Biology , Agriculture and Health Care , V.15 , NO.8, 2015. P .168-164 (ON LINE)

[19] Lei H., Wen SW, Walker M., Determinants of caesarean delivery among women hospitalized for childbirth in a remote population in China, J ObstetGynaecol Can, 25: 937-43, 2003.

[20] Jukelevics N., The Emotional Scars of Cesarean Birth.2001, citedinAjeet S., Jaydeep N., Nandkishore K, Nisha R., Women's knowledge, perceptions, and potential demand towards caesarean section, National Journal of Community Medicine, Sept; Vol 2 ,P. 244, 2011.

[21] Negahban T., Ansari A., whether the fear of delivery can be predict the emergency caesarean among the primigravida women?, $\boldsymbol{J}$ Nurs Midwifery Tehran Med Sci, 14:73-81, 2008.

[22] Naeimi N., GHolami M., Qasemi A. awareness and attitudes of pregnant women admitted to social security hospital in zahedan toward cesarean section, International Journal of Analytical, Pharmaceutical and Biomedical Sciences, Volume: 4: Issue-4: April, 2015

[23] Maharlouei N., Moalaee M., Ajdari S., Zarei M., Lankarani KB., Caesarean delivery in south-western Iran, Med PrincPract, 22:184-8 , 2013, cited in J Res Med Sci, Nov; 18(11): 943-950, 2013. (PubMed)

[24] Faraji R., Zahiri Z., Farjad F., Survey knowledge and attitude of pregnant women in to thedelivery methods, J GuilanUniv Med Sci, 12(46): 69-74, 2003, cited in International Journal of Analytical, Pharmaceutical and Biomedical Sciences, Volume: 4: Issue-4: April , 2015 